\title{
Donor-Specific Regulatory T Cells Acquired from Tolerant Mice Bearing Cardiac Allograft Promote Mixed Chimerism and Prolong Intestinal Allograft Survival
}

\author{
Xiao-Fei Shen ${ }^{1}$, Jin-Peng Jiang ${ }^{2}$, Jian-Jun Yang ${ }^{3}$, Wei-Zhong Wang ${ }^{3}$, Wen-Xian Guan ${ }^{1 \star}$ and \\ Jun-Feng $D u^{4 *}$ \\ 'Department of General Surgery, Affiliated Drum Tower Hospital of Nanjing University Medical School, Nanjing, China, \\ ${ }^{2}$ Department of Rehabilitation Medicine, PLA Army General Hospital, Beijing, China, ${ }^{3}$ Division of Digestive Surgery, Xijing \\ Hospital of Digestive Diseases, Fourth Military Medical University, Xi'an, China, ${ }^{4}$ Department of General Surgery, PLA Army \\ General Hospital, Beijing, China
}

OPEN ACCESS

Edited by:

Brian Duncan Tait,

Australian Red Cross Blood Service,

Australia

Reviewed by:

Bruce Milne Hall,

University of New South Wales,

Australia

Luiza Guilherme,

University of São Paulo, Brazil

*Correspondence:

Wen-Xian Guan

guanwx-nju@hotmail.com;

Jun-Feng Du

dujf66@126.com

Specialty section:

This article was submitted to Alloimmunity and Transplantation,

a section of the journal

Frontiers in Immunology

Received: 21 July 2016 Accepted: 02 November 2016 Published: 17 November 2016

Citation:

Shen X-F, Jiang J-P, Yang J-J, Wang $W-Z$, Guan $W-X$ and Du J-F (2016) Donor-Specific Regulatory $T$ Cells Acquired from Tolerant Mice Bearing Cardiac Allograft Promote

Mixed Chimerism and Prolong Intestinal Allograft Survival.

Front. Immunol. 7:511. doi: 10.3389/fimmu.2016.00511
The induction of donor-specific transplant tolerance has always been a central problem for small bowel transplantation (SBT), which is thought to be the best therapy for endstage bowel failure. With the development of new tolerance-inducing strategies, mixed chimerism induced by co-stimulation blockade has become most potent for tolerance of allografts, such as skin, kidney, and heart. However, a lack of clinically available co-stimulation blockers has hindered efficient application in humans. Furthermore, unlike those for other types of solid organ transplantation, strategies to induce robust mixed chimerism for intestinal allografts have not been fully developed. To improve current mixed chimerism induction protocols for future clinical application, we developed a new protocol using donor-specific regulatory $T$ (Treg) cells from mice with heart allograft tolerance, immunosuppressive drugs which could be used clinically and low doses of irradiation. Our results demonstrated that donor-specific Treg cells acquired from tolerant mice after in vitro expansion generate stable chimerism and lead to acceptance of intestinal allograft. Increased intragraft Treg cells and clonal deletion contribute to the development of SBT tolerance.

Keywords: donor-specific regulatory $\mathrm{T}$ cells, mixed chimerism, transplantation tolerance, small bowel transplantation, bone marrow transplantation

\section{INTRODUCTION}

For patients with end-stage bowel failure, small bowel transplantation (SBT) is recognized as a definitive therapy (1). However, the intestine carries the largest population of lymphoid cells of any transplanted solid organ, which are the least tolerogenic cells in any organ and they have the potential risk of inducing graft-versus-host reaction (2). Therefore, both acute and chronic rejection after SBT is still a great challenge to overcome, which leads to the inferior overall outcome of SBT when compared

Abbreviations: (DS) Treg, (donor-specific) regulatory T cells; APC, antigen-presenting cell; BMC, bone marrow cells; BMDCs, bone marrow-derived dendritic cells; CFSE, carboxyflurescein diacetate succinmidyl ester; CTLA-4, cytotoxic T lymphocyte antigen-4; GM-CSF, granulocyte-macrophage colony-stimulating factor; ICOS, inducible co-stimulator; IFN- $\gamma$, interferon- $\gamma$; IL, interleukin; MLR, mixed lymphocytes reaction; SBT, small bowel transplantation; TNF- $\alpha$, tumor necrosis factor- $\alpha$. 
to that of other transplanted organs (3). Mixed hematopoietic chimerism, in which both donor and host stem cells contribute to hematopoiesis, could help to achieve potent donor-specific tolerance across full MHC barriers (4). Establishment of mixed chimerism through transplantation of donor bone marrow into recipients is one of the most promising strategies for inducing transplantation tolerance (5). Most of the chimerism-inducing protocols require the use of co-stimulation blockade agents (6). Recent results from experimental mouse studies based on costimulation blockade induction of stable mixed chimerism are encouraging. However, translation of tolerance protocols from preclinical animal studies to the clinic is still a major challenge due to the lack of clinically available co-stimulation blockers (6). Regulatory $\mathrm{T}$ (Treg) cells have long been recognized to play a critical role in self-tolerance, but administration of Treg cells on their own does not induce robust immune tolerance across MHC barriers in immunocompetent hosts (7). Combining Treg cell therapy with co-stimulation blockade and rapamycin has been tested to promote full MHC-mismatched mixed chimerism, and the results are encouraging $(8,9)$. Furthermore, recipient donorspecific Treg (DSTreg) cells are thought to be the most potent to promote mixed chimerism among all types of Treg cells (9). However, whether recipient DSTreg cells could lead to intestinal allograft acceptance after establishment of mixed chimerism has not been fully elucidated.

Our previous work (10) demonstrated that allograft acceptance can be established by donor-specific transfusion with complete blockade of inducible co-stimulator (ICOS)/B7h signaling. Furthermore, this allograft acceptance was transferable and maintained by $\mathrm{CD} 4{ }^{+} \mathrm{CD} 25^{+} \mathrm{T}$ cells from recipient mice with longterm allograft survival, and these Treg cells could be expanded in vitro and exert donor-specific immune negative regulation. In the present study, a non-myeloablative protocol of combined transfusion of DSTreg cells and donor bone marrow, together with cytotoxic T lymphocyte antigen CTLA4Ig (abatacept, clinically available co-stimulation blocker) and rapamycin, was developed to establish mixed chimerism in lightly irradiated mice. We evaluated the possibility of mixed chimerism to induce murine SBT tolerance and tried to develop new methods for clinical use.

\section{MATERIALS AND METHODS}

\section{Animals}

Male mice of inbred strains BALB/c (H-2 $\left.{ }^{\mathrm{d}}\right), \mathrm{C} 57 \mathrm{BL} / 6\left(\mathrm{~B} 6, \mathrm{H}-2^{\mathrm{b}}\right)$, and $\mathrm{C} 3 \mathrm{H} / \mathrm{HeJ}\left(\mathrm{C} 3 \mathrm{H}, \mathrm{H}-2^{\mathrm{k}}\right)$ aged $6-8$ weeks were obtained from the Experimental Animal Center of the Fourth Military Medical University (Xi'an, China). All the animal experiments were carried out following the Guidelines for the Care and Use of Laboratory Animals of the Fourth Military Medical University and were approved by the ethical review committee of the Fourth Military Medical University.

\section{Bone Marrow Preparation and Treatment Regimens}

Age-matched male mice received 3 Gy total body irradiation (Day -1$)$, co-stimulation blockade with abatacept $(0.5 \mathrm{mg} / \mathrm{mouse}$,
Day 2) (Orencia, Bristol-Myers Squibb Pharmaceuticals, Princeton, NJ, USA), and three doses of rapamycin $(0.1 \mathrm{mg} / \mathrm{mouse}$, Days -1 , 0 , and 1) (LC Laboratories, Woburn, MA, USA) were injected intravenously on day 0 with $2.0 \times 10^{7}$ unseparated bone marrow cells (BMCs) harvested from MHC-full mismatched BALB/c donors (8-12 weeks old), with or without expanded fresh Treg cells or expanded DSTreg cells $\left(3 \times 10^{6}\right.$ per mouse $)$. The preparation of $\mathrm{BM}$ of $\mathrm{BALB} / \mathrm{c}$ mice was performed as previously described (11).

\section{SBT and Histological Graft Assessment}

Heterotopic SBT was performed using a modified technique of Guo et al. (11). Briefly, about $5 \mathrm{~cm}$ of ileum was removed from donor mice on a vascular pedicle consisting of the superior mesenteric artery, abdominal aorta, and portal vein. The donor abdominal aorta was anastomosed end-to-side to the recipient infrarenal aorta and the donor portal vein to the recipient inferior vena cava. The proximal and distal ends of the intestinal graft were exteriorized stomas. Intestinal allografts were scored according to the following definitions: 0 , no rejection; 1 , scattered apoptotic crypt cells; 2 , focal crypt destruction; and 3, mucosal ulceration with or without transmural necrosis (11).

\section{Skin Grafting}

Full-thickness tail skin from donor $(\mathrm{BALB} / \mathrm{c})$ and fully mismatched third-party $(\mathrm{C} 3 \mathrm{H})$ mice was grafted 100 days after SBT and visually inspected at short intervals thereafter. Grafts were considered to be rejected when $<10 \%$ remained viable (12).

\section{Isolation of CD4 ${ }^{+} \mathrm{CD}^{2} 5^{+}$Treg Cells}

$\mathrm{CD} 4{ }^{+} \mathrm{CD} 25^{+}$Treg cells were isolated as previously described (8). Fresh or DSTreg cells were isolated from spleen of naïve or tolerant $\mathrm{B} 6$ mice. $\mathrm{CD} 4{ }^{+} \mathrm{CD} 25^{+}$cells were purified by magnetic bead separation using negative selection for $\mathrm{CD} 4^{+}$and subsequent positive selection for $\mathrm{CD} 25^{+}$by incubating $\mathrm{CD} 4^{+}$enriched cells with phycoerythrin (PE)-conjugated $\alpha$-CD25 (PC61) followed by $\alpha$-PE microbeads $\left(\mathrm{CD} 4{ }^{+} \mathrm{CD} 25^{+}\right.$Regulatory T-cell Isolation Kit; MiltenyiBiotec, Bergisch Gladbach, Germany) (13). The purity of separated cells was $>90 \%$.

\section{Generation of Dendritic Cells}

Bone marrow-derived dendritic cells (BMDCs) were induced in the medium of $4 \mathrm{ml}$ complete RPMI 1640, by adding $20 \mathrm{ng} / \mathrm{ml}$ granulocyte-macrophage colony-stimulating factor (GM-CSF). On days 3 and 5 , the culture medium was replaced by fresh medium with GM-CSF (20 ng/ml). On day 6, cells were additionally treated with $1 \mu \mathrm{g} / \mathrm{ml}$ lipopolysaccharide for $24 \mathrm{~h}$ to further induce the maturation of DC. Loosely adherent cells and those in the culture supernatant were harvested by gentle washing with PBS for further use.

\section{Treg-Cell Proliferation Assay}

Sorted $\mathrm{CD} 4^{+} \mathrm{CD} 8^{-} \mathrm{CD} 25^{+} \mathrm{T}$ cells $\left(5 \times 10^{4}\right)$ from naïve and tolerant B6 mice bearing cardiac grafts were cultured for 14 days at $37^{\circ} \mathrm{C}$ in $5 \% \mathrm{CO}_{2}$ with $2 \times 10^{5} \mathrm{BALB} / \mathrm{c}$ BMDCs in the presence or absence of interleukin (IL)-2 (1000 U/ml) and rapamycin (100 nM), alone 
or in combination. In some experiments, T cells were prelabeled with a solution of $5 \mathrm{mM}$ carboxyflurescein diacetate succinmidyl ester (CFSE; Invitrogen, Carlsbad, CA, USA), followed by culture for 7 days with various stimuli. CFSE dilution was analyzed on a Beckman Coulter Epics XL.

\section{CD4 ${ }^{+}$CD25 ${ }^{+}$Treg Cell Immunosuppression Assay}

Mixed lymphocytes reaction (MLR) was used to assess the suppressive activity of $\mathrm{CD} 4^{+} \mathrm{CD} 25^{+}$Treg cells as previously described $(14,15)$. Briefly, CD $4^{+} \mathrm{CD} 8^{-} \mathrm{CD} 25^{+}$and $\mathrm{CD} 4^{+} \mathrm{CD} 8^{-} \mathrm{CD} 25^{-} \mathrm{T}$ cells with ratios ranged from 1:1 to $1: 16$ were cultured for $72 \mathrm{~h}$ in 96-well flat-bottomed plates with anti-CD3 $(5 \mu \mathrm{g} / \mathrm{ml})$ and irradiated splenocytes (APCs). After 3 days in culture, ${ }^{3} \mathrm{H}$-thymidine was added to each well for an additional $18 \mathrm{~h}$. ${ }^{3} \mathrm{H}$-thymidine incorporation was measured on a $\beta$-scintillation counter (15).

\section{MLR in Mixed Chimeras}

MLRs in chimeras were performed as described previously (12, 16). Briefly, $4 \times 10^{5}$ responder splenocytes were incubated in triplicate with $4 \times 10^{5}$ irradiated (30 Gy) stimulator cells of either $\mathrm{B} 6$ (recipient), $\mathrm{BALB} / \mathrm{c}$ (donor), or $\mathrm{C} 3 \mathrm{H}$ (third party) origin or with medium only. After $72 \mathrm{~h}$ incubation, cells were pulsed with $[3 \mathrm{H}]$-thymidine (Amersham Biosciences, Little Chalfont, Bucks, UK) for $18 \mathrm{~h}$. Incorporated radioactivity was measured using scintillation fluid in a $\beta$ counter. Stimulation indices were calculated in relation to medium controls.

\section{Isolation of Lamina Propria Lymphocytes in the Small Intestine}

Isolation of lamina propria cells from the small intestine was performed as previously described (17). The whole transplanted small intestine was cut into pieces $0.5 \mathrm{~cm}$ in length and shaken twice at $250 \mathrm{rpm}$ for $30 \mathrm{~min}$ at $37^{\circ} \mathrm{C}$ in Hanks' Balanced Salt Solution (Life Technologies) supplemented with 5\% (v/v) fetal bovine serum (CellGro) containing $2 \mathrm{mM}$ EDTA. The remaining intestinal tissues were washed and shaken for $30 \mathrm{~min}$ at $37^{\circ} \mathrm{C}$ in RPMI 1640 plus 5\% (v/v) fetal bovine serum and type IV collagenase ( $1 \mathrm{mg} / \mathrm{ml}$; Sigma). Cell suspensions were enriched by centrifugation at room temperature at $500 \mathrm{~g}$ for $20 \mathrm{~min}$ in $40 \% / 70 \%$ Percoll (GE Healthcare) in RPMI 1640. The interface layer cells were used for further analysis.

\section{Flow Cytometry, Monoclonal Antibodies, and Reagents}

Peripheral blood was collected, the red cells were lysed, and the remaining cells washed with a whole blood lysis kit (R\&D Systems, Minneapolis, MN, USA). Peripheral blood leukocytes were stained with fluorochrome-conjugated anti-CD3, anti-CD11b, anti-GR1, anti-B220, anti-H-2Kb, anti-Vb11, anti-H-2Kd, anti-Vb8.1/8.2, anti-Vb5.1/5.2 (PharMingen, San Diego, CA, USA), anti-CD4, anti-CD8 (Caltag, Burlingame, CA, USA), or immunoglobulin isotype controls (PharMingen, Caltag). Donor chimerism was expressed as a percentage that was calculated using the following formula: $\left(\mathrm{H}-2 \mathrm{~K}^{\mathrm{d}+}\right.$ cells/total gated cells $) \times 100(11)$.
The following monoclonal antibodies (mAbs) were purchased from BD Biosciences PharMingen: anti-mCD4-APC-CY7, anti-mCD45RB-PE, anti-mCD44-PE, anti-mCD62L-PE, antimCTLA4-PE, anti-mGITR-PE. Anti-mCD4-FITC, anti-mCD8$\mathrm{PE}$, anti-mCD4-APC, anti-mFoxp3-PE, and anti-mCD25-PE-CY5 were purchased from eBioscience.

\section{ELISA for Intestinal Inflammatory Cytokines}

Small intestine cytokines were measured with a mouse-specific cytokines ELISA kit (eBioscience, San Diego, CA, USA). Tissues were homogenized in ice-cold RIPA buffer [150 $\mathrm{mM} \mathrm{NaCl}$, $50 \mathrm{mM}$ Tris- $\mathrm{HCl}, 1 \mathrm{mM}$ EDTA, and 1\% Triton-X (pH 7.4)], and samples processed for mouse-specific ELISA kits.

\section{Statistical Analysis}

Survival data were analyzed using the Kaplan-Meier method with the log-rank test to verify the significance of the difference in survival between the groups. Data are presented as mean \pm SD. Student's unpaired $t$-test for comparison of means was used to compare groups. $P<0.05$ was considered to be of significant difference.

\section{RESULTS}

\section{Expansion of Fresh and Donor-Specific CD4 ${ }^{+}$CD25 $^{+}$Treg Cells}

Previously, we have shown that DSTreg cells from tolerant B6 mice bearing cardiac grafts induce cardiac graft acceptance in irradiated B6 mice (Figure 1A) (10). To expand CD4 ${ }^{+} \mathrm{CD} 25^{+}$ Treg cells, we first purified single splenocytes from naïve or tolerant $\mathrm{B} 6$ mice using a CD4 ${ }^{+} \mathrm{CD} 25^{+}$Regulatory T-cell Isolation Kit (MiltenyiBiotec) (18). The purity of separated cells was confirmed to be $>90 \%$ (Figure 1C). Numerous in vitro and in vivo studies have suggested the critical role of rapamycin in expanding naturally occurring $\mathrm{CD} 4{ }^{+} \mathrm{CD} 25^{+} \mathrm{Foxp} 3^{+}$Treg cells that are normally found in the naïve splenic $\mathrm{CD} 4^{+} \mathrm{T}$-cell compartment, as well as in maintaining their suppressive function in vitro (19-21). We used similar culture conditions with some modification. After 14 days stimulation, we found that DSTreg and fresh Treg cells could be expanded stably in vitro, and the combination of rapamycin plus IL-2 resulted in greatest expansion of fresh $\mathrm{CD} 4{ }^{+} \mathrm{CD} 25^{+}$Treg cells $(23.7 \pm 1.8$-fold) and DSTreg cells $(31.5 \pm 2.1$-fold) (Figure 1B). The purity of the expanded cells was $>95 \%$ (Figure 1C). Furthermore, DSTreg cells proliferated more efficiently than fresh Treg cells in response to IL-2 and rapamycin (Figure 1B). When analyzing the expression of surface markers by flow cytometry, DSTreg cells from tolerant mice expressed equal levels of CD62L, CD44, CTLA-4, and GITR as fresh Treg cells derived from naïve mice did (data not shown). Ex vivo fresh Treg and DSTreg cells were also assessed for suppression in MLR assays. Expanded DSTreg cells displayed a more powerful inhibitory function than fresh Treg, expanded fresh Treg, and DSTreg cells (Figure 1D). We also confirmed that the enhanced suppressive function of expanded DSTreg cells was donor specific (Figure 1E). Therefore, we established a method that could expand DSTreg cells in vitro. 


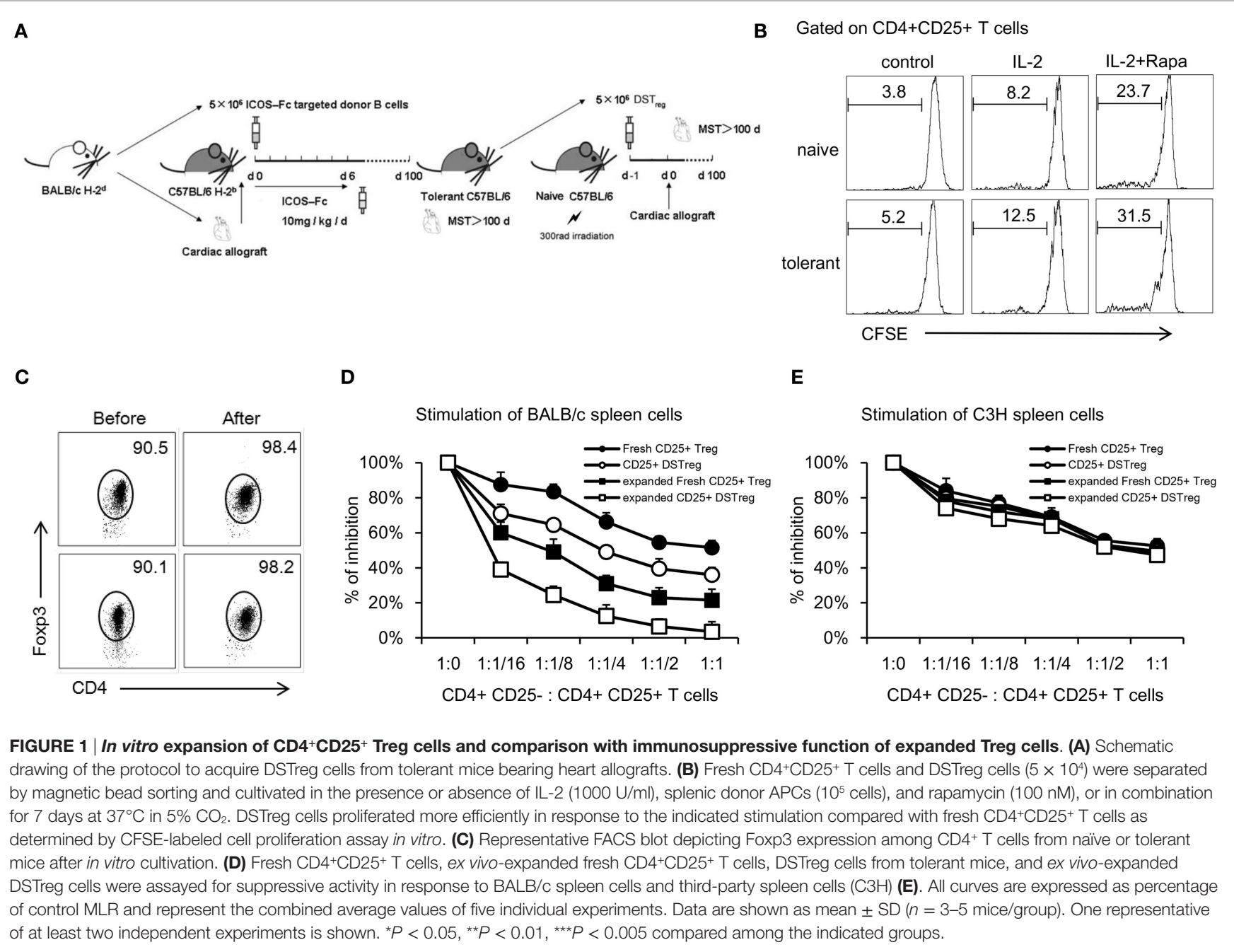

\section{Donor-Specific Treg Cell Treatment Leads to Multilineage Mixed Chimerism}

Next, we investigated the potency of expanded DSTreg and expanded fresh Treg cells for induction of chimerism and tolerance. Under the cover of co-stimulation blockade with abatacept, a low dose of 3 Gy irradiation and three doses of rapamycin, B6 mice received a conventional dose of fully mismatched BALB/c BM $\left(2 \times 10^{7}\right.$ cells per mouse), together with different numbers of expanded DSTreg or fresh Treg cells $\left(10^{5}, 5 \times 10^{5}, 10^{6}, 2 \times 10^{6}\right.$, or $3 \times 10^{6}$ per mouse). Most recipients treated with Treg cells developed mixed chimerism, whereas no chimerism was detected without Treg cell treatment 4 weeks after BMT (Figure 2A). BMT recipients treated with expanded DSTreg cells displayed higher chimerism rates than those with expanded fresh Treg cells, and cell numbers could even be reduced to $5 \times 10^{5}$ cells/ mouse (Figure 2A). Chimerism levels in recipients treated with expanded DSTreg cells were also significantly higher than those in recipients treated with expanded fresh Treg cells (Figures 2B,C). The best induction of stable mixed chimerism was achieved with injection of $3 \times 10^{6}$ cells/mouse (Figure 2C); therefore, we used this number of cells for subsequent experiments. We also discovered that BMT recipients treated with expanded DSTreg cells achieved substantial levels of T cells, B cells, granulocytes, and macrophages chimerism at indicated time points post-BMT, while the levels of chimerism in recipients treated with expanded fresh Treg cells were relatively low (Figure 2D). Therefore, these results suggest that expanded DSTreg cells were more potent than expanded fresh Treg cells in the induction of hematopoietic chimerism.

\section{Clinical Manifestation and Graft Survival Rates}

After the establishment of BM chimerism, we further investigated whether mixed chimerism induced by Treg cells could promote intestinal allograft tolerance. SBT was performed 4 weeks after BMT. The intestinal grafts in the allogeneic group were all rejected within 14 days. Intestinal grafts in recipients that received BM cell infusion showed similar survival rates to those in the allogeneic group (Figure 3A), while intestinal grafts in the BM cells + expanded fresh Treg cells group survived for an extended period of 50 days after transplantation (Figure 3A). Intestinal grafts in the chimera recipients induced 

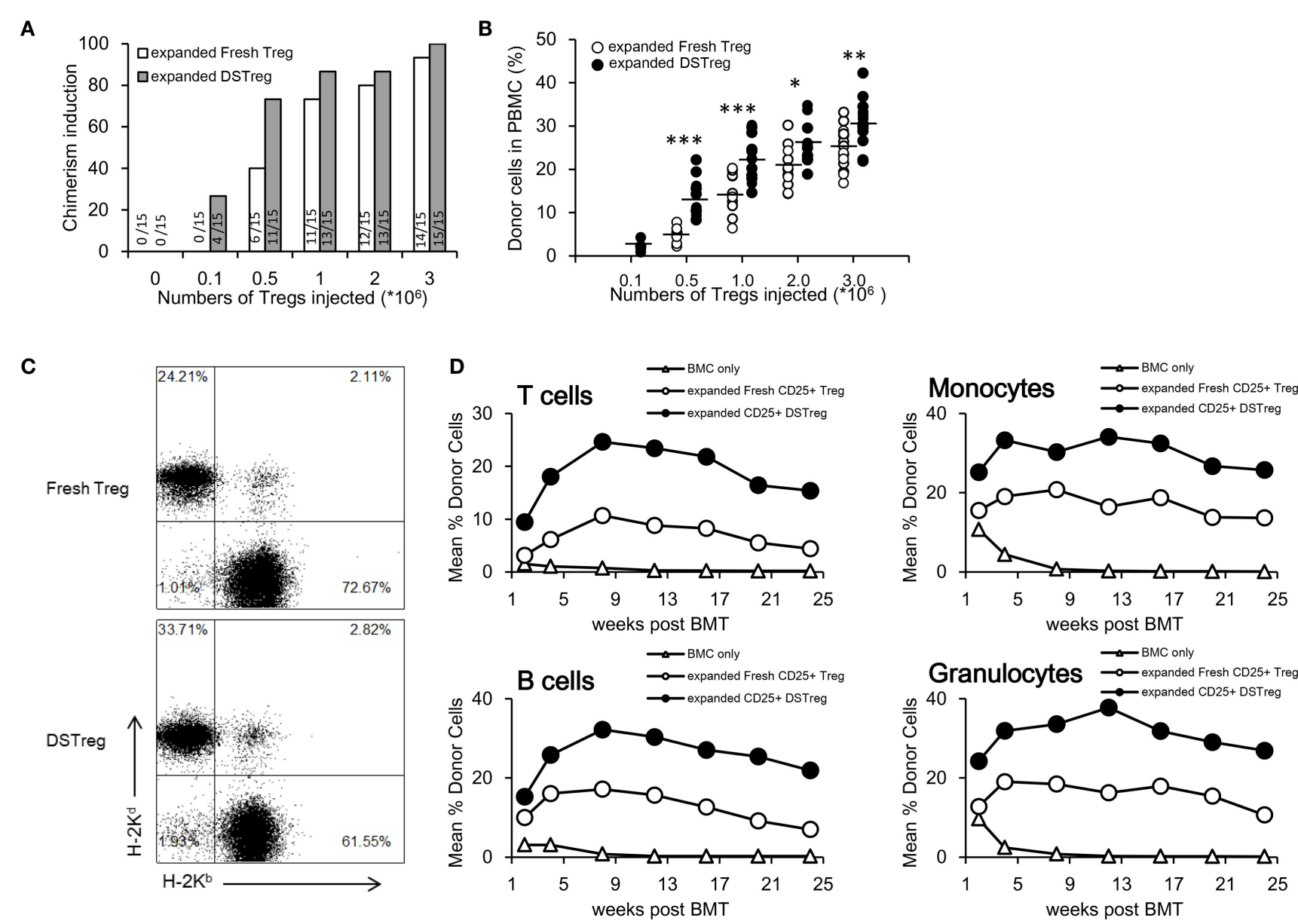

FIGURE 2 | DSTreg cell treatment together with low-dose irradiation leads to multilineage mixed chimerism. (A) Groups of C57BL/6J mice were transplantated with fully mismatched BALB/c BM cells $\left(2 \times 10^{7}\right)$ under low doses of irradiation (3 Gy total body irradiation at day -1 ), co-stimulation blockade with abatacept (CTLA-4-lg) (0.05 mg at day 2), and three doses of rapamycin (0.1 mg at days 1,0 , and 2$)$ were additionally treated with or without different numbers of expanded DSTreg cells, or expanded fresh Treg cells at day 0. Percentages of successfully induced chimeras are shown. Chimerism was considered to be established if donor cells were detectable by flow cytometry within both the myeloid lineage and at least one lymphoid lineage for the duration of follow-up. (B) Hematopoietic reconstitution was assessed at 3 weeks after BMT. Values for individual mice are shown; bars indicated means. (C) Typical FACS plots of H-2K (recipient) versus $\mathrm{H}-2 \mathrm{~K}^{\mathrm{d}}$ (donor) staining were carried out 3 weeks after BMT. (D) Donor $\left(\mathrm{H}-2 \mathrm{D}^{d}\right)$ chimerism among leukocytes was assessed by flow cytometry of peripheral blood at multiple time points $\left(2,4,8,12,16,20\right.$, and 24 weeks post-BMT) and is shown as mean percentage. ${ }^{\star} P<0.05$, ${ }^{\star \star} P<0.01$, ${ }^{\star \star \star} P<0.005$ compared among the indicated groups.

by expanded DSTreg cells survived for the longest period, and more than half of the grafts survived for the duration of followup, without the presence of both acute and chronic rejection (Figure 3A). When comparing the histological results among each group, chimeras induced through DSTreg cell infusion demonstrated viable and best-preserved structure of mucosa and villi (Figure 3B). The stoma in this group also had good structure. The relative rejection score was also significantly lower in chimeras induced by BM and DSTreg cell treatment (Figure 3C).

The main factors controlling organ rejection are the balance between cellular immune responses mediated by T-helper cells that produce numerous proinflammatory cytokines and inhibitory cytokines. Thus, the grafts concentrations of inflammatoryresponse-related Th1/Th2 and Th17/Treg cytokines were also assayed with ELISA. The concentrations of tumor necrosis factor (TNF)- $\alpha$, IL-17A, IL-23, and interferon (IFN)- $\gamma$ all increased gradually in the allogeneic control group (Figure 3D). Compared to the allogeneic control group, the concentrations of IL-23, IFN- $\gamma$, and IL-17A in the grafts of chimeras were significantly lower on days 5, 7, and 11 than those in the allogeneic control group (Figure 3D). The concentrations of inhibitory cytokines transforming growth factor- $\beta$ and IL-10 were significantly higher in the chimera group than in the allogeneic group on days 5,7 , and 11 (Figure 3E), and the levels of these two inhibitory cytokines were higher in the BM + DSTreg cell group than in the $\mathrm{BMC}+$ fresh Treg cells group (Figure 3E). These results suggest that recipients treated with BMC + DSTreg cells can better accept small bowel allografts, with low levels of inflammatory response and acute rejection. 


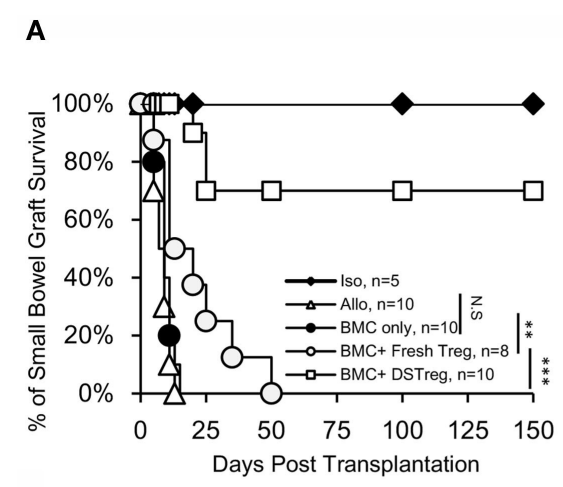

D
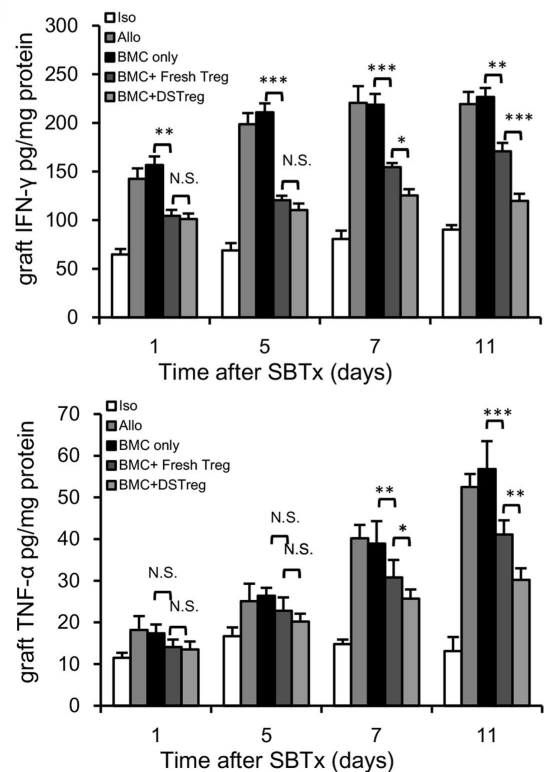

B

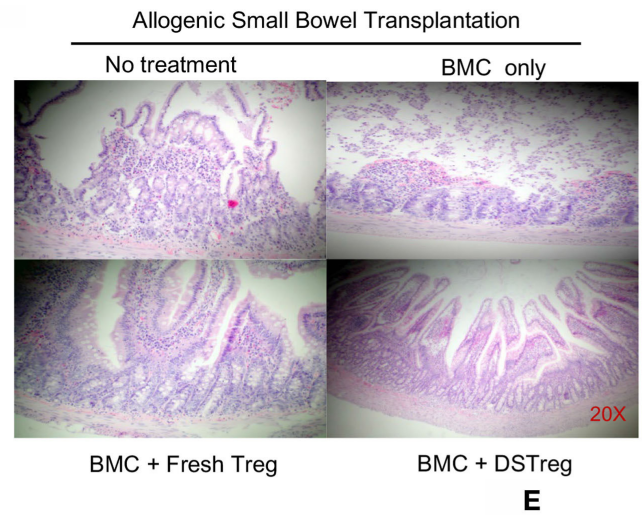

C

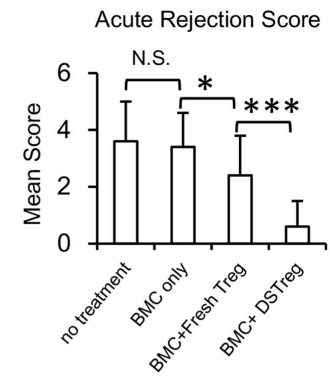

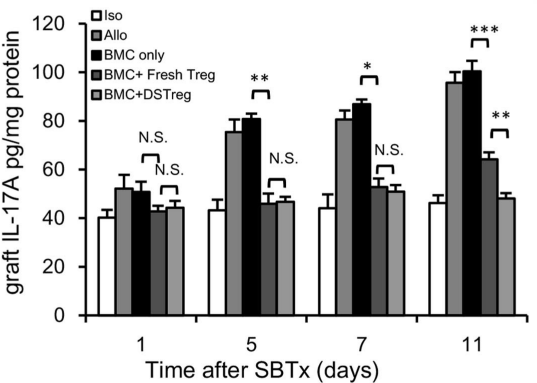

100 品o
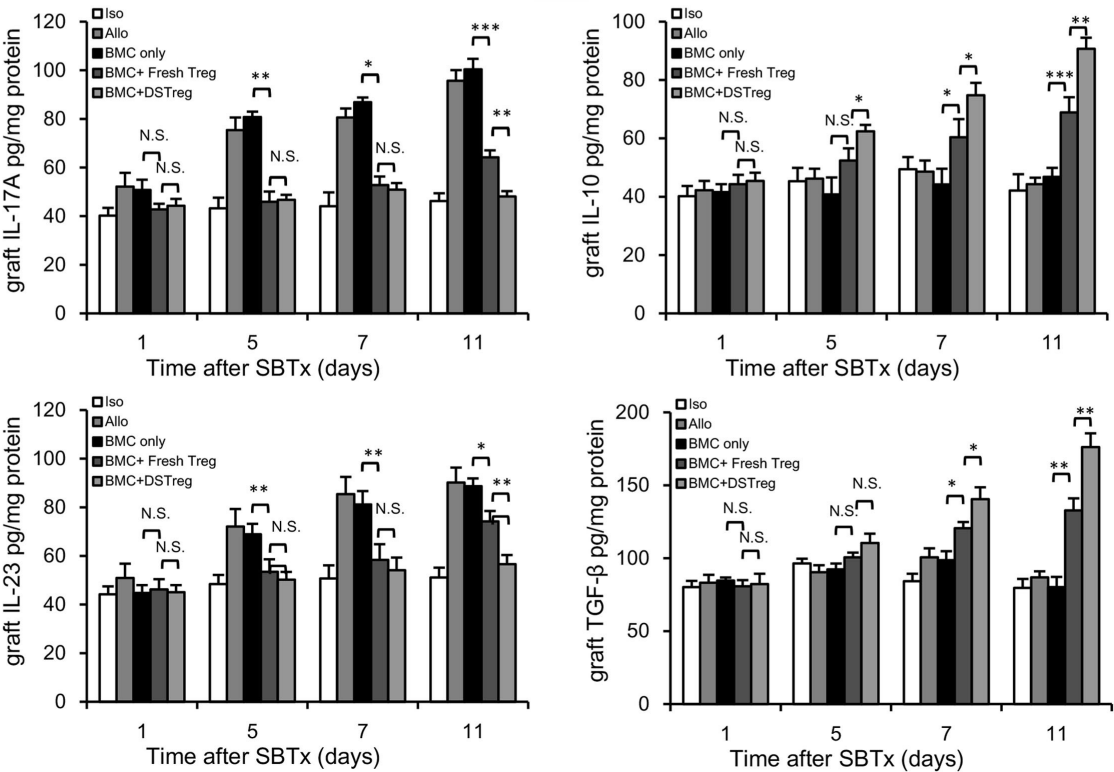

FIGURE 3 | Chimeras induced by DSTreg cells developed full donor-specific intestine allograft tolerance, and tolerant chimeras displayed hypoinflammatory responses in the intestinal allografts. (A) Graft survival of intestinal allografts. (B) Representative hematoxylin-and-eosin-stained (original magnification: $\times 100$ ) sections of intestinal allografts from recipients treated with low-dose irradiation (3 Gy) and BM cells, with or without expanded DSTreg cells, and expanded fresh Treg cells (14 days post-SBT). (C) Allografts were assigned an acute rejection score by a blinded pathologist. (D,E) Cytokine concentrations in the recipient intestinal allografts were measured by ELISA on days 1, 5, 7, and 11 after SBT. Data are shown as mean \pm SD $(n=4-7)$. One representative of at least two independent experiments is shown. ${ }^{*} P<0.05,{ }^{* *} P<0.01,{ }^{* \star *} P<0.005$ compared among the indicated groups.

\section{Increased Infiltration of CD4 ${ }^{+}$Foxp3 ${ }^{+}$Treg Cells in Small Bowel Grafts and Deletion of Donor-Reactive T Cells of Mixed Chimeras Induced by BM and DSTreg Cell Infusion}

To assess tolerance in these fresh Treg and DSTreg induced chimeras, in vitro MLR assays were performed to evaluate self-reactivity, donor-reactivity, and third-party reactivity. In chimeras treated with Treg cells, responsiveness toward the donor was almost reduced to the level of self-reactivity (Figure 4A), whereas third-party reactivity was preserved (Figure 4A). $\mathrm{CD}^{+} \mathrm{Foxp}^{+}$Treg cells have been implicated to play a crucial role in homeostasis of intestinal immunity (18, $22,23)$, and dysregulation of the number and function of Treg cells contributes to the development of intestinal transplantation rejection $(24,25)$. Previous results have also suggested higher levels of inhibitory cytokines relative to Treg cells in recipients treated with expanded DSTreg cells. Therefore, we obtained intestinal grafts and directly assessed the infiltration of $\mathrm{CD}^{+}{ }^{+} \mathrm{Foxp}^{+}{ }^{+}$Treg cells as previously described (17). The percentage of infiltrating $\mathrm{CD} 4^{+} \mathrm{Foxp}^{+}{ }^{+}$Treg cells was significantly higher in grafts of chimeras treated with $\mathrm{BM}+$ expanded DSTreg cells compared to those of chimeras treated with BM cells only or BM + expanded fresh Treg cells (Figures 4B,C). Although the percentage of Foxp $3^{+}$Treg cells in $\mathrm{CD}^{+} \mathrm{T}$ cells in the spleen of recipients treated with expanded DSTreg cells was higher than that in recipients treated with expanded fresh Treg cells, no significant difference was discovered (Figure 4D). The frequency of $\mathrm{CD} 4^{+} \mathrm{Foxp}^{3}$ Treg cells in peripheral blood is 


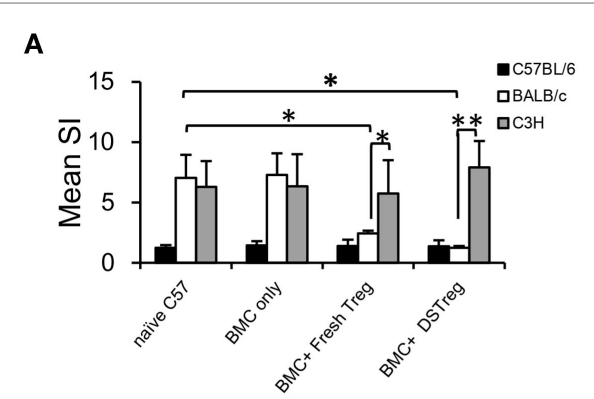

B

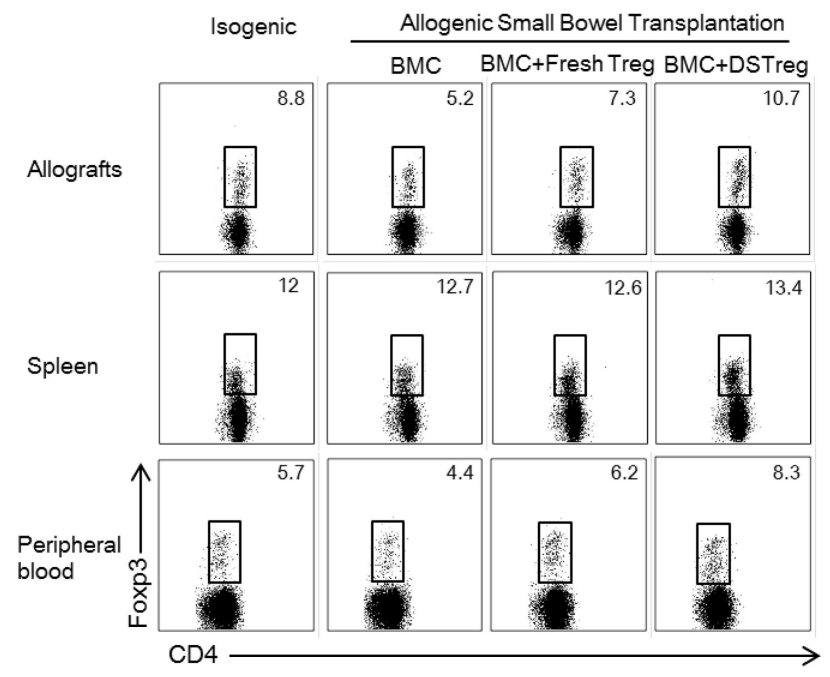

C

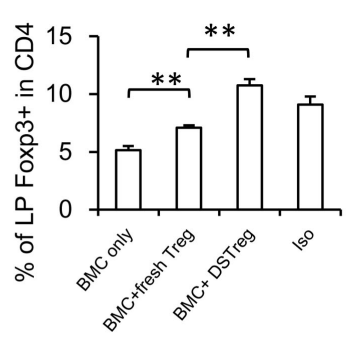

D

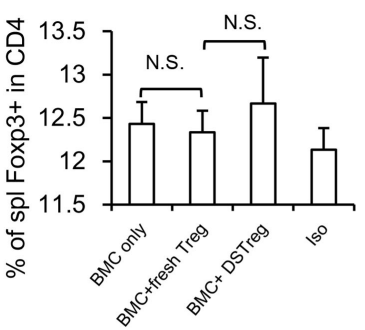

E

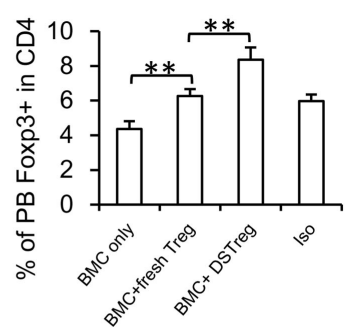

$\mathbf{F}$
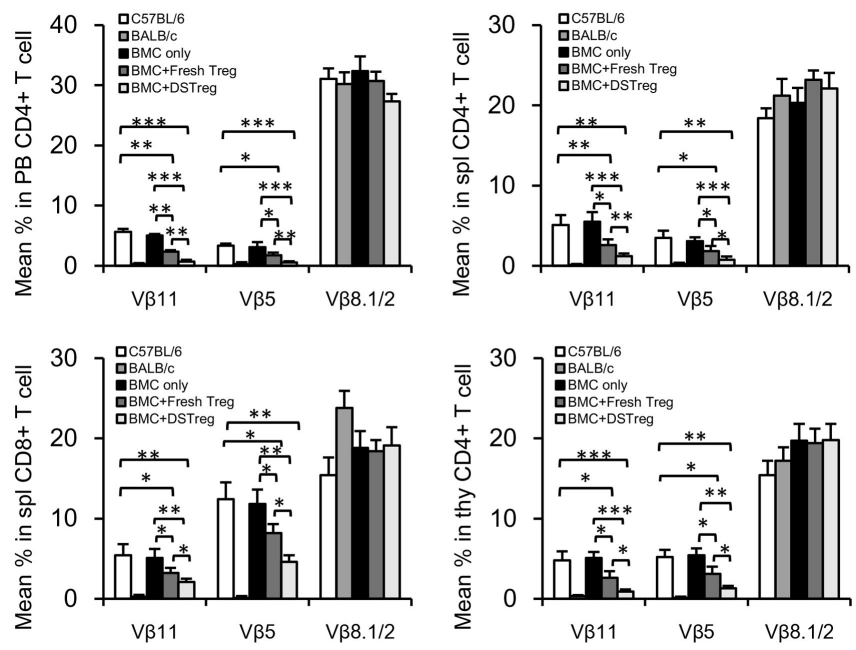

FIGURE 4 | Regulatory mechanism and clonal deletion contribute to intestinal allograft acceptance in chimeras treated with expanded DSTreg cells. (A) Donor reactivity was assessed in MLRs at 8 weeks post-BMT. Donor-specific responses and third-party reactivity were measured in each group. Simulation indices were calculated by dividing the mean cpm from responses against recipient (C57BL/6J), donor (BALB/C), or third-party (C3H) stimulator cells by mean background cpm (i.e., cpm with no stimulator population). The percentage of CD4+Foxp3+ cells in recipient allografts (B,C), spleen (D), and peripheral blood (E) was measured by multicolor flow cytometry on day 14 after SBT. (F) Deletion of donor-reactive $T$ cells in chimeras was shown by assessing percentages of $V \beta 11$, $V \beta 5$, and $V \beta 8$. Multicolor flow cytometry was used for measurement in selected mice at 8 weeks post-BMT. Chimeras treated with expanded DSTreg cells showed significant peripheral and central clonal deletion among donor-reactive $T$ cells, as measured by percentage of $V_{\beta} 11$ and $V_{\beta} 5$ (but not $V_{\beta} 8$ ). Data are shown as mean $\pm \mathrm{SD}(n=4-6)$. One representative of at least three independent experiments is shown. ${ }^{\star} P<0.05,{ }^{\star \star} P<0.01,{ }^{\star \star \star} P<0.005$ compared among the indicated groups.

negatively correlated with severity of graft versus host diseases in humans (26) and is also regarded as a biomarker for hematopoietic cell transplantation outcomes (27). Similar results were also obtained in our model (Figure 4E).

Mixed chimerism was induced in our model and chimeric recipients displayed hyporesponsiveness to donor antigens; therefore, deletion of intrathymic and peripheral donorreactive T cells might also underlie the lack of responsiveness to donor antigens. To test this hypothesis, we examined the levels of certain $\mathrm{V} \beta$ subunits within the $\mathrm{T}$-cell receptor repertories. The frequencies of $\mathrm{V} \beta 11^{+}$and $\mathrm{V} \beta 5^{+}$peripheral $\mathrm{CD} 4^{+} \mathrm{T}$ cells were low in chimeras treated with expanded DSTreg cells, which suggested the establishment of peripheral clonal deletion, while it was incomplete in chimeras with BM cells, lowdose irradiation, and expanded fresh Treg cells (Figure 4F). No deletion was seen in recipients without Treg cell treatment (Figure 4F). Furthermore, significant intrathymic deletion was also achieved in recipients treated with expanded DSTreg cells (Figure 4F).

\section{Donor-Specific Skin Graft Acceptance in Mixed Chimeras Receiving BM and DSTreg Cell Infusion, and Maintenance of Normal Immune Response to Third-Party Grafts}

To determine whether or not tolerance was donor-specific in recipients treated with DSTreg cells after SBT, skin transplantation was performed 100 days after SBT. Mice receiving DSTreg cells that did not accept small bowel grafts rejected both BALB/c and $\mathrm{C} 3 \mathrm{H}$ skin grafts within 14 days, while mice achieving small bowel grafts permanently also accepted BALB/c skin grafts permanently. These mice also rejected $\mathrm{C} 3 \mathrm{H}$ skin grafts, which further showed that mice that accepted small bowel grafts achieved donor-specific transplantation tolerance (Figure 5). 


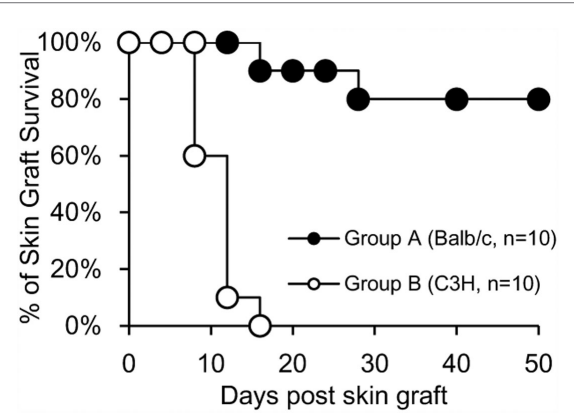

FIGURE 5 | Mixed chimeras of DSTreg cell infusion group received donor-specific skin grafts and retained normal immune response to third-party grafts. Skin transplantation was performed 100 days after SBT in recipients (C57BL/6) treated with DSTreg cells, and survival curve of skin grafts from donor-specific Balb/c mice and $\mathrm{C} 3 \mathrm{H}$ mice was shown. Donor-specific Balb/c skin grafts survived in most chimeras, whereas $\mathrm{C} 3 \mathrm{H}$ skin was rejected. ${ }^{\star} P<0.05,{ }^{\star \star} P<0.01,{ }^{\star \star \star} P<0.005$ compared among the indicated groups.

\section{DISCUSSION}

We $(28)$ and others $(23,29)$ have suggested the critical role of Treg cells in maintaining intestinal homeostasis, and better control of the number and function of Treg cells in GALT, especially in the intestine, might be a promising prospect for the acceptance of intestinal allografts. How to maintain longterm DSTreg cells and/or expand them in vivo has always been a central problem in immune tolerance, and isolating sufficient numbers of Treg cells for in vivo use is also a significant clinical challenge (21). Previously, we have shown that donor-specific transfusion with complete blockade of ICOS/B7h signaling can achieve immune tolerance (10). Furthermore, this allograft acceptance is transferable and mediated by $\mathrm{CD} 4{ }^{+} \mathrm{CD} 25^{+} \mathrm{Foxp}^{+}$ $\mathrm{T}$ cells from recipient mice. To acquire large numbers of these DSTreg cells for further use, we tried to expand the cells in vitro. Mature DCs have been suggested to be the most potent APCs to expand antigen-specific Treg cells in the presence of highdose IL-2 (30). Since spleen cells are a mixture of many cell types with only $1-1.5 \%$ being DCs, among which the majority are in an immature state, we used BMDCs as donor-specific APCs to stimulate Treg cells, with or without rapamycin or IL-2, alone or in combination. After 2 weeks of co-culture, our results clearly showed that BMDCs could expand these DSTreg cells with potent suppressive function in vitro in the presence of IL-2 and rapamycin, which is consistent with other in vitro and in vivo results (19-21). In vitro results also demonstrated that these expanded DSTreg cells displayed more powerful immunosuppressive function. However, it has been shown that infusion of DSTreg cells alone only delays $\mathrm{CD} 4^{+}$ T-cell-mediated skin graft rejection and $\mathrm{CD} 8^{+} \mathrm{T}$-cell-mediated allograft rejection $(11,31,32)$, and results from highly immunogenic organ transplantation models are still frustrating (11). We (4) also acquired similar results in SBT, which drove us to seek better strategies for immune tolerance in SBT. Studies have also suggested that rodent models for tolerance through mixed chimerism are among the most robust, which might be the best candidate for clinical trials $(8,33,34)$. Recently, longterm stable kidney allograft survival without maintenance immunosuppression was also achieved by infusion of BM cells (35). Therefore, chimerism might be a promising strategy for intestinal transplantation.

Various mixed chimerism protocols have been developed including the use of immunosuppressive drugs, co-stimulation blockade $(36,37)$, Foxp $3^{+}$Treg cell application $(8,38)$, and T-cell depletion $(11,39)$. Among all these, strategies based on the use of co-stimulation blockade are the most potent at inducing mixed chimerism (6). However, there are few reports on protocols for promoting stable intestinal allograft acceptance. Guo et al. have conducted a series of studies on biological agents that delay intestinal acute rejection and found that chimerism with anti-CD40L mAb, CTLA4-Ig, donor BM, and busulfan prolong intestinal allograft survival (11). However, their strategy still failed to achieve long-term survival of intestinal allografts with different levels of chimerism and persistence of donor-reactive $\mathrm{T}$ cells in recipients. Furthermore, they could not identify Treg cells in chimeric recipients bearing intestinal allografts, which suggest the absence of a regulatory mechanism in this model. Recently, combining Treg therapy with non-cytoreductive BMT has been suggested to promote acceptance of heart grafts in mice (12). Although this kind of Treg-cell-induced strategy achieved immune tolerance, the levels of chimerism observed were low and depletion of donor-reactive $\mathrm{T}$ cells was also incomplete, which might not be suitable for application to immunogenic organs like the intestine $(8,12)$. Furthermore, in addition to tolerization of intrathymic newly developing $\mathrm{T}$-cell repertoire, pre-existing mature donor-reactive $\mathrm{T}$ cells also need to be tolerized through peripheral mechanisms in such protocols (9).

In our study, we found that DSTreg cells from tolerant mice stably induced mixed chimerism and further promoted the intestinal allograft acceptance. The percentage of Treg cells in the intestine was also significantly high in the DSTreg-cellinduced chimeras, which might have contributed to the low levels of inflammatory response. Similar results were found in peripheral blood, which strongly suggests achievement of immune tolerance in these recipient mice. Besides, clonal deletion is considered the backbone of tolerance through chimerism (40), and most groups investigating tolerance associated with chimerism-inducing strategies have reported deletion of donor-reactive $\mathrm{CD} 4^{+} \mathrm{T}$ cells (11). We also observed significant deletion of ${\mathrm{V} \beta 5^{+}}^{+}$and $\mathrm{V} \beta 11^{+} \mathrm{MMTV}$-reactive $\mathrm{CD} 4^{+}$ and $\mathrm{CD} 8^{+} \mathrm{T}$ cells in DSTreg-cell-induced chimeras. Therefore, clonal deletion and regulatory mechanisms both contribute to promote allograft acceptance in our study. We also further demonstrated that immune tolerance induced in our model was donor specific.

In conclusion, we have developed a new mixed-chimerisminducing protocol using the DSTreg cells acquired from tolerant mice bearing heart allografts and have promoted the acceptance of intestinal allografts. These results underlie the clinical potential of Treg-cell-based chimerism and subsequent prevention 
of solid organ transplantation rejection that is highly immunogenic. Further studies on determining the origin (donor or recipient) and migration pattern of Treg cells in these tolerant mice bearing intestinal allografts are needed so that they can be used clinically.

\section{AUTHOR CONTRIBUTIONS}

J-FD and W-XG conceived and designed the experiments; X-FS and J-PJ performed the experiments; J-JY and W-ZW analyzed the data; J-PJ, X-FS, and J-JY contributed reagents/materials/ analysis tools; J-FD and X-FS wrote the paper.

\section{REFERENCES}

1. Fishbein TM. Intestinal transplantation. N Engl J Med (2009) 361:998-1008. doi:10.1056/NEJMra0804605

2. von Websky MW, Kalff JC, Schafer N. Current knowledge on regulation and impairment of motility after intestinal transplantation. Curr Opin Organ Transplant (2015) 20:303-7. doi:10.1097/MOT.0000000000000190

3. Berger M, Zeevi A, Farmer DG, Abu-Elmagd KM. Immunologic challenges in small bowel transplantation. Am J Transplant (2012) 12(Suppl 4):S2-8. doi:10.1111/j.1600-6143.2012.04332.x

4. Du JF, Li SY, Yu B, Bai X. Treg-based therapy and mixed chimerism in small intestinal transplantation: does Treg +BMT equal intestine allograft tolerance? Med Hypotheses (2011) 76:77-8. doi:10.1016/j.mehy.2010.08.035

5. Kawai T, Cosimi AB, Spitzer TR, Tolkoff-Rubin N, Suthanthiran M, Saidman SL, et al. HLA-mismatched renal transplantation without maintenance immunosuppression. N Engl J Med (2008) 358:353-61. doi:10.1056/ NEJMoa071074

6. Pilat $\mathrm{N}$, Hock $\mathrm{K}$, Wekerle $\mathrm{T}$. Mixed chimerism through donor bone marrow transplantation: a tolerogenic cell therapy for application in organ transplantation. Curr Opin Organ Transplant (2012) 17:63-70. doi:10.1097/ MOT.0b013e32834ee68b

7. Joffre O, Santolaria T, Calise D, Al Saati T, Hudrisier D, Romagnoli P, et al. Prevention of acute and chronic allograft rejection with CD4+CD25+Foxp3+ regulatory T lymphocytes. Nat Med (2008) 14:88-92. doi:10.1038/nm1688

8. Pilat N, Baranyi U, Klaus C, Jaeckel E, Mpofu N, Wrba F, et al. Tregtherapy allows mixed chimerism and transplantation tolerance without cytoreductive conditioning. Am J Transplant (2010) 10:751-62. doi:10.1111/j.1600-6143.2010.03018.x

9. Pilat N, Wekerle T. Mechanistic and therapeutic role of regulatory $\mathrm{T}$ cells in tolerance through mixed chimerism. Curr Opin Organ Transplant (2010) 15:725-30. doi:10.1097/MOT.0b013e3283401755

10. Du JF, Wang C, Wang WZ, Li MB, Liang HL, Guan WX. Transferable cardiac allograft acceptance induced by transfusion of donor B cells with impaired inducible costimulator/B7h allorecognition. Transplant Proc (2009) 41:1840-3. doi:10.1016/j.transproceed.2009.01.106

11. Guo Z, Wang J, Dong Y, Adams AB, Shirasugi N, Kim O, et al. Long-term survival of intestinal allografts induced by costimulation blockade, busulfan and donor bone marrow infusion. Am J Transplant (2003) 3:1091-8. doi:10.1034/j.1600-6143.2003.00127.x

12. Pilat N, Farkas AM, Mahr B, Schwarz C, Unger L, Hock K, et al. T-regulatory cell treatment prevents chronic rejection of heart allografts in a murine mixed chimerism model. J Heart Lung Transplant (2014) 33:429-37. doi:10.1016/j. healun.2013.11.004

13. Mahr B, Unger L, Hock K, Pilat N, Baranyi U, Schwarz C, et al. IL-2/ alpha-IL-2 complex treatment cannot be substituted for the adoptive transfer of regulatory T cells to promote bone marrow engraftment. PLoS One (2016) 11(1):e0146245. doi:10.1371/journal.pone.0146245

14. Wang H, Zhao L, Sun Z, Sun L, Zhang B, Zhao Y. A potential side effect of cyclosporin A: inhibition of $\mathrm{CD} 4(+) \mathrm{CD} 25(+)$ regulatory $\mathrm{T}$ cells in mice. Transplantation (2006) 82:1484-92. doi:10.1097/01.tp.0000246312.89689.17

\section{ACKNOWLEDGMENTS}

We thank Ying Xing and Qiang He for their excellent technical assistance.

\section{FUNDING}

This work was supported by National Natural Science Foundation of China (No. 81000189, 81571563, J-FD, and 81500432, X-FS), China Postdoctoral Science Foundation (No.2014M552695, J-FD), PLA Youth Culturing Project of Medical Science (No.14QNP009, J-FD), and the Fundamental Research Funds for the Central Universities (No. 021414380106, X-FS).

15. Xia GL, Kovochich M, Truitt RL, Johnson BD. Tracking ex vivo-expanded $\mathrm{CD} 4(+) \mathrm{CD} 25(+)$ and $\mathrm{CD} 8(+) \mathrm{CD} 25(+)$ regulatory T cells after infusion to prevent donor lymphocyte infusion-induced lethal acute graft-versus-host disease. Biol Blood Marrow Transplant (2004) 10:748-60. doi:10.1016/ j.bbmt.2004.07.004

16. Wekerle T, Kurtz J, Ito H, Ronquillo JV, Dong V, Zhao G, et al. Allogeneic bone marrow transplantation with co-stimulatory blockade induces macrochimerism and tolerance without cytoreductive host treatment. Nat Med (2000) 6:464-9. doi:10.1038/74731

17. Du J, Shen X, Zhao Y, Hu X, Sun B, Guan W, et al. Wip1-deficient neutrophils significantly promote intestinal ischemia/reperfusion injury in mice. Curr Mol Med (2015) 15:100-8. doi:10.2174/1566524015666150114122929

18. Veenbergen S, Samsom JN. Maintenance of small intestinal and colonic tolerance by IL-10-producing regulatory T cell subsets. Curr Opin Immunol (2012) 24:269-76. doi:10.1016/j.coi.2012.03.004

19. Battaglia M, Stabilini A, Roncarolo MG. Rapamycin selectively expands CD4(+)CD25(+)FoxP3(+) regulatory T cells. Blood (2005) 105:4743-8 doi:10.1182/blood-2004-10-3932

20. Ogino H, Nakamura K, Iwasa T, Ihara E, Akiho H, Motomura $Y$, et al. Regulatory $\mathrm{T}$ cells expanded by rapamycin in vitro suppress colitis in an experimental mouse model. J Gastroenterol (2012) 47:366-76. doi:10.1007/ s00535-011-0502-y

21. Shin HJ, Baker J, Leveson-Gower DB, Smith AT, Sega EI, Negrin RS. Rapamycin and IL-2 reduce lethal acute graft-versus-host disease associated with increased expansion of donor type CD4(+)CD25(+)Foxp3(+) regulatory T cells. Blood (2011) 118:2342-50. doi:10.1182/blood-2010-10-313684

22. Haghikia A, Jorg S, Duscha A, Berg J, Manzel A, Waschbisch A, et al. Dietary fatty acids directly impact central nervous system autoimmunity via the small intestine. Immunity (2015) 43:817-29. doi:10.1016/j.immuni.2015.09.007

23. Kim KS, Hong SW, Han D, Yi J, Jung J, Yang BG, et al. Dietary antigens limit mucosal immunity by inducing regulatory $\mathrm{T}$ cells in the small intestine. Science (2016) 351:858-63. doi:10.1126/science.aac5560

24. Xie FT, Cao JS, Zhao J, Yu Y, Qi F, Dai XC. IDO expressing dendritic cells suppress allograft rejection of small bowel transplantation in mice by expansion of Foxp3+ regulatory T cells. Transpl Immunol (2015) 33:69-77. doi:10.1016/j. trim.2015.05.003

25. Rieger K, Loddenkemper C, Maul J, Fietz T, Wolff D, Terpe H, et al. Mucosal FOXP3+ regulatory $\mathrm{T}$ cells are numerically deficient in acute and chronic GvHD. Blood (2006) 107:1717-23. doi:10.1182/blood-2005-06-2529

26. Engelhardt BG, Jagasia M, Savani BN, Bratcher NL, Greer JP, Jiang A, et al. Regulatory T cell expression of CLA or alpha(4)beta(7) and skin or gut acute GVHD outcomes. Bone Marrow Transplant (2011) 46:436-42. doi:10.1038/ bmt.2010.127

27. Engelhardt BG, Sengsayadeth SM, Jagasia M, Savani BN, Kassim AA, Lu PC, et al. Tissue-specific regulatory T cells: biomarker for acute graftvs-host disease and survival. Exp Hematol (2012) 40:974-82. doi:10.1016/ j.exphem.2012.08.002

28. Shen X, Du J, Guan W, Zhao Y. The balance of intestinal Foxp3+ regulatory $\mathrm{T}$ cells and Th17 cells and its biological significance. Expert Rev Clin Immunol (2014) 10:353-62. doi:10.1586/1744666X.2014.882232 
29. Nishio J, Baba M, Atarashi K, Tanoue T, Negishi H, Yanai H, et al. Requirement of full TCR repertoire for regulatory T cells to maintain intestinal homeostasis. Proc Natl Acad Sci U S A (2015) 112:12770-5. doi:10.1073/pnas. 1516617112

30. Yamazaki S, Iyoda T, Tarbell K, Olson K, Velinzon K, Inaba K, et al. Direct expansion of functional CD25(+) CD4(+) regulatory T cells by antigen-processing dendritic cells. J Exp Med (2003) 198(2):235-47. doi:10.1084/ jem.20030422

31. Xia G, He J, Zhang Z, Leventhal JR. Targeting acute allograft rejection by immunotherapy with ex vivo-expanded natural CD4+ CD25+ regulatory T cells. Transplantation (2006) 82:1749-55. doi:10.1097/01.tp.0000250731. 44913.ee

32. Xia G, He J, Leventhal JR. Ex vivo-expanded natural CD4+CD25+ regulatory $\mathrm{T}$ cells synergize with host $\mathrm{T}$-cell depletion to promote long-term survival of allografts. Am J Transplant (2008) 8:298-306. doi:10.1111/j.16006143.2007.02088.x

33. Sykes M, Szot GL, Swenson KA, Pearson DA. Induction of high levels of allogeneic hematopoietic reconstitution and donor-specific tolerance without myelosuppressive conditioning. Nat Med (1997) 3:783-7. doi:10.1038/ nm0797-783

34. Wekerle T, Sykes M. Mixed chimerism and transplantation tolerance. Annu Rev Med (2001) 52:353-70. doi:10.1146/annurev.med.52.1.353

35. Kawai T, Sachs DH, Sprangers B, Spitzer TR, Saidman SL, Zorn E, et al. Long-term results in recipients of combined HLA-mismatched kidney and bone marrow transplantation without maintenance immunosuppression. Am J Transplant (2014) 14:1599-611. doi:10.1111/ajt.12731

36. Kean LS, Durham MM, Adams AB, Hsu LL, Perry JR, Dillehay D, et al. A cure for murine sickle cell disease through stable mixed chimerism and tolerance induction after nonmyeloablative conditioning and major histocompatibility complex-mismatched bone marrow transplantation. Blood (2002) 99:1840-9. doi:10.1182/blood.V99.5.1840

37. Wekerle T, Sayegh MH, Ito H, Hill J, Chandraker A, Pearson DA, et al. Anti-CD154 or CTLA4Ig obviates the need for thymic irradiation in a non-myeloablative conditioning regimen for the induction of mixed hematopoietic chimerism and tolerance. Transplantation (1999) 68:1348-55. doi:10.1097/00007890-199911150-00022

38. Joffre O, Gorsse N, Romagnoli P, Hudrisier D, van Meerwijk JP. Induction of antigen-specific tolerance to bone marrow allografts with CD4+CD25+ T lymphocytes. Blood (2004) 103:4216-21. doi:10.1182/blood-2004-01-0005

39. Ito H, Takeuchi Y, Shaffer J, Sykes M. Local irradiation enhances congenic donor pluripotent hematopoietic stem cell engraftment similarly in irradiated and nonirradiated sites. Blood (2004) 103:1949-54. doi:10.1182/ blood-2003-09-3249

40. Hock K, Mahr B, Schwarz C, Wekerle T. Deletional and regulatory mechanisms coalesce to drive transplantation tolerance through mixed chimerism. Eur J Immunol (2015) 45:2470-9. doi:10.1002/eji.201545494

Conflict of Interest Statement: The authors declare that the research was conducted in the absence of any commercial or financial relationships that could be construed as a potential conflict of interest.

Copyright (c) 2016 Shen, Jiang, Yang, Wang, Guan and Du. This is an open-access article distributed under the terms of the Creative Commons Attribution License (CC BY). The use, distribution or reproduction in other forums is permitted, provided the original author(s) or licensor are credited and that the original publication in this journal is cited, in accordance with accepted academic practice. No use, distribution or reproduction is permitted which does not comply with these terms. 